\title{
SELECTION OF COLLISION DETECTION MODEL ON THE BASIS OF A COLLISION OF INCOMPATIBLE VEHICLES
}

\author{
P. Aleksandrowicz*
}

\begin{abstract}
In today's world, many road users are exposed to the risk of accident. The consequences of the potential crash depend not only on the collision speed, but also on the type of vehicle. The article shows the problems connected with choosing an appropriate collision detection model in the case of a collision of two incompatible vehicles. In addition, directions and values of acceleration of inertia during the crash have been determined and presented. The case study is a collision of a motor car with a combine-harvester in which the problem of incompatibility is particularly noticeable. Simulation calculations were performed using the V-SIM4 code. Experimental verification has demonstrated practical application of a collision detection volumetric model, which best represents the impact of such a vehicle. The article also includes information on how to use the collision detection model in the V-SIM4 code, which may be used by court judges, assessors and investigators, as verification of these collision computers codes for cars is unavailable in the literature. Therefore, the subject of the article is both cognitive and practical.
\end{abstract}

\section{Keywords: VSIM code, crash model, crash compatibility, directions of acceleration of inertia}

\section{Introduction}

Road traffic has always involved the risk of accident, collision or failure. The paper of Knopik et al. (2017) discusses the risk of failure and demonstrates the impact of prevention measures on the risk reduction. On the other hand, an analysis of an accident requires selection of a suitable, collision detection model, which is relevant for the analyzed case, as discussed in the work of Aleksandrowicz (2017c). In the works of Wicher (2012) and Yang et al. (2012) compatibility issues and crash tests are presented, as well as experimental results of collisions. Additional equipment has been installed in order to provide better protection for the car users, as shown in the works of Lambert et al. (2002). The effects of collision between a truck and a motor car are presented, for example, in the work (Aleksandrowicz, 2017b). Accident analysis experts use computer code with Multi Body Systems modeling (MBS). The most commonly used are PC-Crash, Virtual Crash and V-SIM (http://www.dsd.at; http://www.vcrashusa.com; www.cyborgidea.com.pl). In the works (Dima et al., 2014; Semela et al., 2007) the accidents were analyzed with the aid of PC Crash and Virtual Crash. In these studies a good representation of the crash pattern was obtained. These computer code can also be used in a design process, as discussed in the work of Porteš et al. (2017) on the example of a truck. The force of contact between vehicles is also a very important element of impact reconstruction. Some papers (Kostek et al., 2017b,c) identify contact parameters: stiffness during compression and restitution as well as the coefficient of restitution. Besides the contact parameters assumed by the expert have an essential effect on the simulation result, which has been demonstrated in some papers (Kostek et al., 2017a,d). Whereas, based on the simulation results, it is also possible to identify insurance frauds by verifying vehicle crashes as compared to the collision circumstances reported, which has been discussed in other papers (Aleksandrowicz, 2017a,b). The experimental verification of a vehicle collision with a combine-harvester in V-SIM4 code has not been performed yet. The article deals with the problem of such an unusual collision and provides guidelines for experts and researchers for the analysis of such crash. The article deals with the problem of such an unusual collision, and provides experts and researchers with additional clues to analyze collisions when the vehicle incompatibility is inevitable.

Piotr Aleksandrowicz, PhD.: Machine Maintenance Department, Institute of Machinery Operation and Transport, University of Science and Technology, Al. prof. S. Kaliskiego 7; 85 796, Bydgoszcz; Poland, p.aleksandrowicz@utp.edu.pl 


\section{Object analysis and models of collision detections}

Daewoo Lanos vehicle (total weight $-1.360 \mathrm{~kg}$ ) with a driver and two passengers inside, and Fortschritt 512 combine-harvester (total weight $-8.300 \mathrm{~kg}$ ) with an operator inside, were involved in the crash. The accident took place on a dry, clean, smooth asphalt road that was 4.1 meters wide. Before the place of collision, 55.3 meter long skid marks were found - the vehicle was not equipped with ABS. Below, Figure 1 shows the site of the accident.
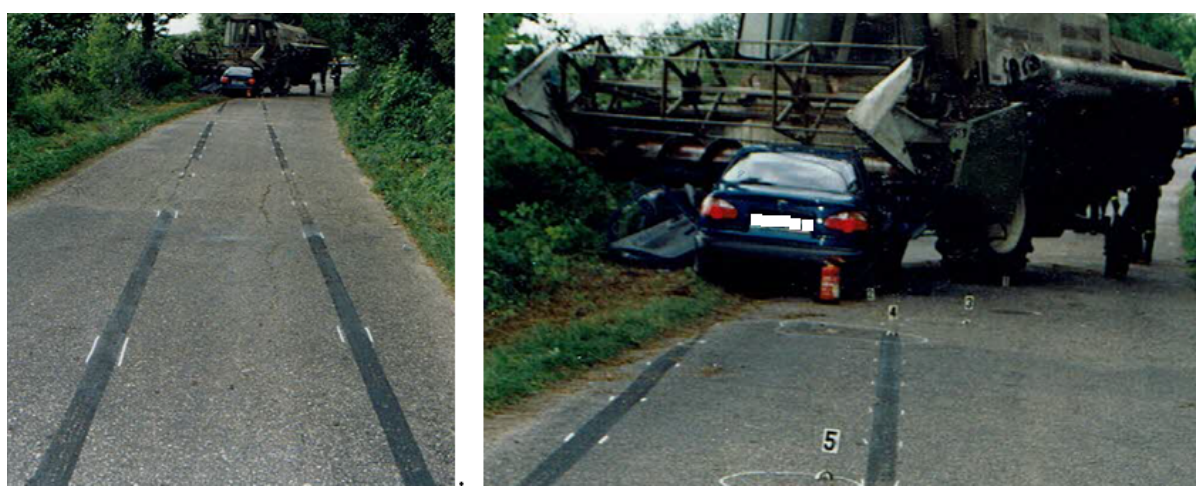

Fig. 1: View of the site of the accident.

The car motion in the V-SIM4 code is described as a rigid body movement in a three-dimensional space with ten degrees tolerance for a typical four-wheels vehicle. Two collision detection models offered in this computer code - 2D and 3D - were taken into consideration in the crash analysis (Bułka, 2016).

\subsection{D collision detection model}

2D model uses collision detection of objects based on the projections of their silhouettes on the ground. Vector profiles of vehicles that represent their shapes, can be imported from the external database (https://www.autoview.at; https://www.the-blueprints.com). Figure 2 illustrates the 2D collision detection model in the analyzed example.

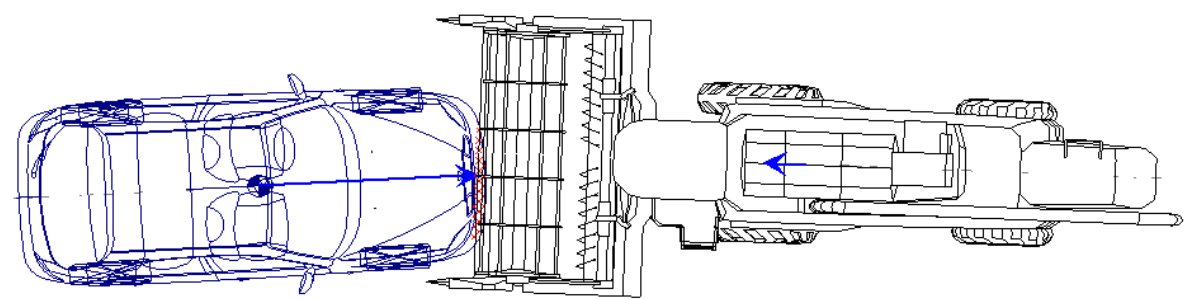

Fig. 2: Two-dimensional model of collision detection.

\subsection{D collision detection model}

V-SIM4 code applies the solution that uses a three-dimensional map of points inside the body of the simulated object. Collision detection tests involve checking whether the body grid interior points of both vehicles overlap. Figure 3 shows a volumetric model of the vehicles' bodies composed of triangles, which is applied in the calculation computer code.

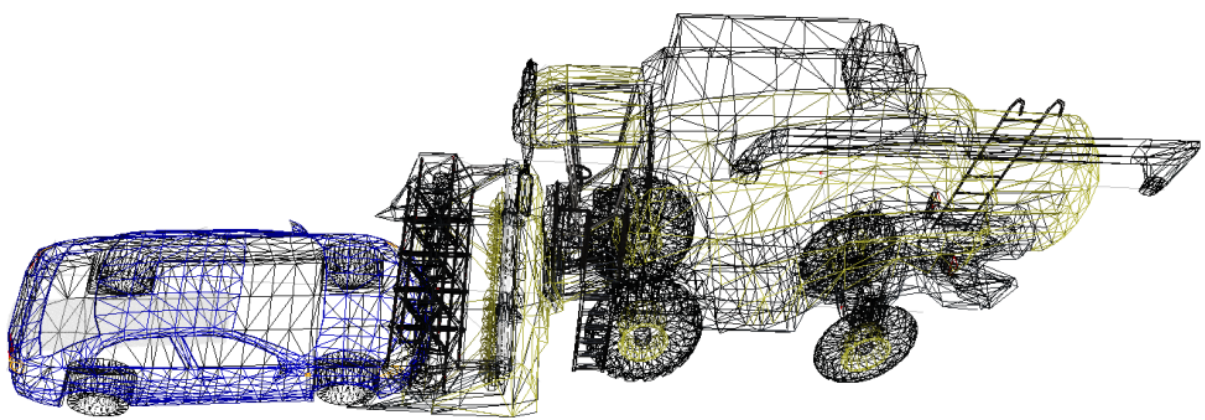

Fig. 3: Volumetric collision detection model. 


\section{Case study - own research}

The vehicles' positions after the collision were measured and documented in the accident investigation record. Car Daewoo Lanos drove into a combine-harvester, as shown in Figure 4.

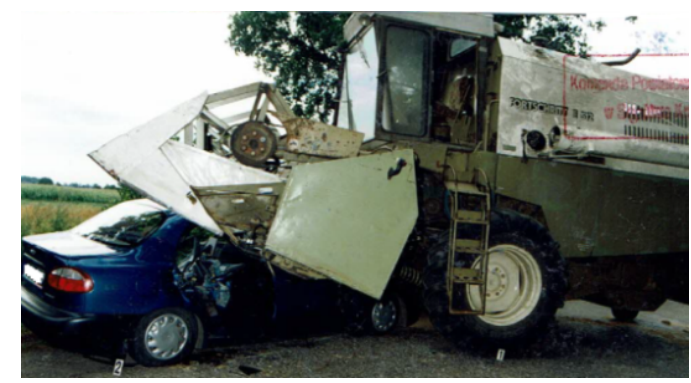

Fig. 4: Post-accident position of Daewoo Lanos.

Results of matching the positions of Daewoo Lanos provided by the crash post collision simulation are shown in Table 1 below. Matching degree (\%) $\mathrm{S}_{\mathrm{x}}, \mathrm{S}_{\mathrm{y}}$ of the Daewoo gravity center distance in $x, y$ axles and rotation angle $\varnothing$ around the vertical symmetry axis of the car position obtained from simulation to its actual position measured after the collision was adopted to be a measure of the collision detection model.

Tab. 1: The results of matching the vehicle positions achieved in the simulation to the actual post-crash positions.

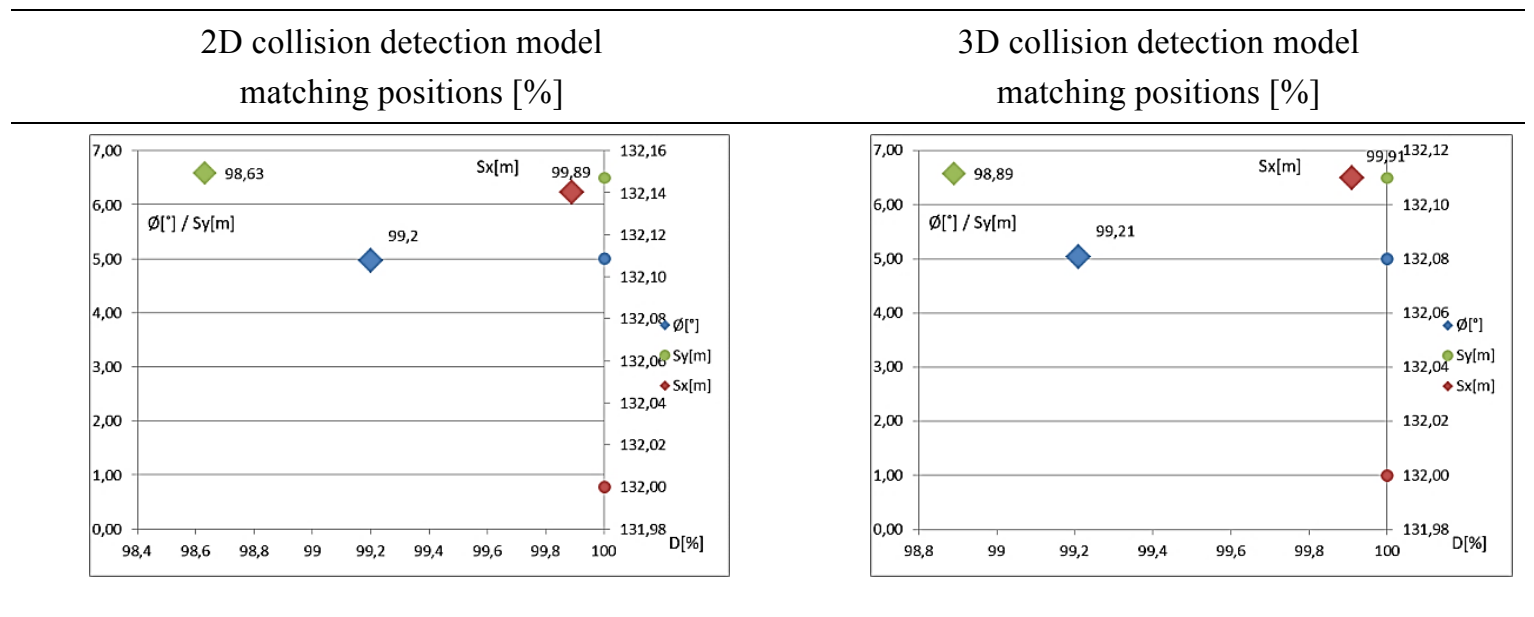

The calculations performed in V-SIM4 code show that the collision detection volumetric model best reflects the collision of the motor car and the combine-harvester. The expert, after assessing adequacy of the collision detection model, should proceed to further calculations to determine the values and directions of accelerations of inertia acting on passengers of the cars. Below, Figure 5 presents Daewoo Lanos acceleration time course when colliding with the combine-harvester, for the volume model that got the best match.

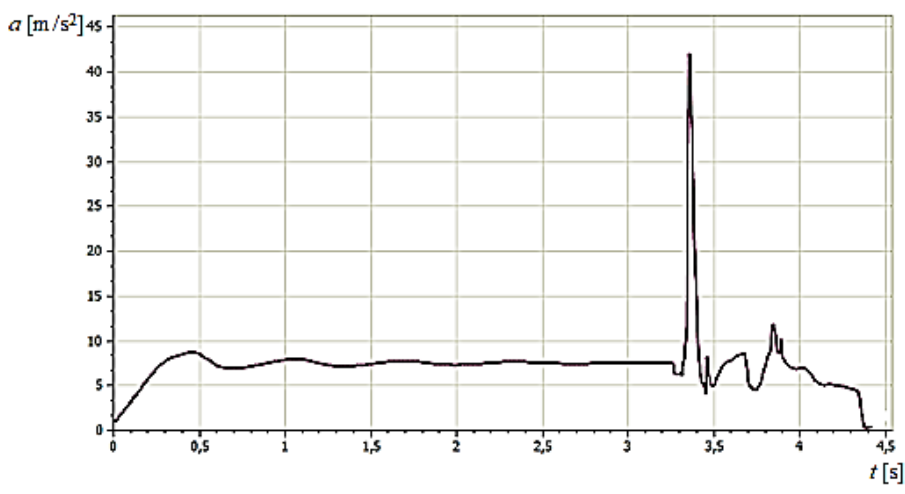

Fig. 5: Changes in acceleration during a crash.

Significant changes in the action direction from the right at the time $t=3.36 \mathrm{~s}$, straight ahead in time $t=3.46 \mathrm{~s}$ and from the left in time $t=3.84 \mathrm{~s}$ are represented by red arrows in Figure 6 , these changes are also presented for Daewoo movement in the video (https://youtu.be/ioqzYrFBQk0). 


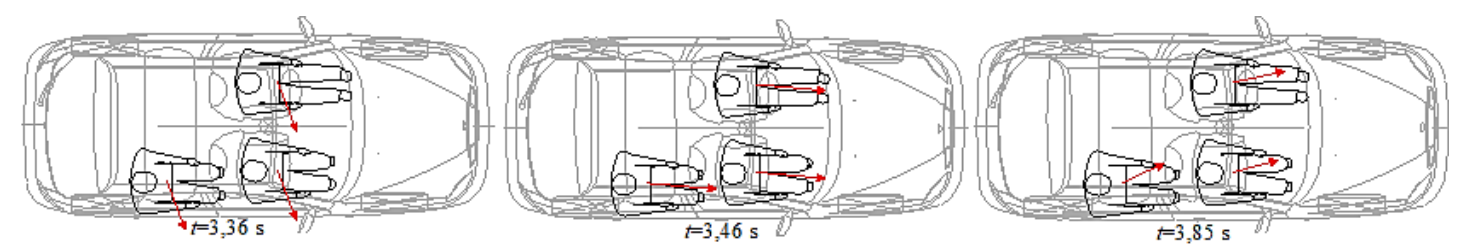

Fig. 6: Directions of acceleration of inertia.

\section{Conclusions}

The research shows that the best simulation view of the accident between a motor car and a combineharvester has been provided by using a collision detection volumetric model. The match of the vehicle position after a crash, obtained in the simulation, to the actual post-crash positions of vehicles measured at the accident site, in the longitudinal axis $\mathrm{S}_{\mathrm{x}}$ was $99.91 \%$, in the transverse axis $\mathrm{S}_{\mathrm{y}} 98.89 \%$ and the angle of rotation around the vertical axis of symmetry was $\varnothing=99.21 \%$. The overlapping results given in Table 1 must be related to the fact that in 2D collision detection model the simulation objects are considered to be vertical cuboids with the base being a projection of their styling. It results in an excessively early contact identification. That defect, however, is not found in the 3D model in which a 3D vehicle body shape mesh is applied. For the 3D collision detection model the values of accelerations in inertia were also calculated. Their maximum value was $47.6 \mathrm{~m} / \mathrm{s}^{2}$, which is presented in Fig.5. It occurs at time $t=3.36 \mathrm{~s}$ when the front of Daewoo went under the combine-harvester header and caused contact with the machine front elements, which resulted in a rapid car braking.

\section{References}

Aleksandrowicz, P. (2017a) Analysis of vehicle collisions with the SDC method, in: Engineering Mechanics 2017, Brno University of Technology, Brno, pp. 78-81.

Aleksandrowicz, P. (2017b) Verifying a truck collision applying the SDC method, in: Proc. $58^{\text {th }}$ International Conference of Machine Design Departments 2017, Praque, Czech Republic, pp. 14-19.

Aleksandrowicz, P. (2017c) Verifying the application of the models of crash and collision detection of incompatible vehicles in: Engineering Mechanics 2017, Brno University of Technology, Brno, pp. 82-85.

Bułka, D. (2016) V-SIM4 - User manual, CIBID Cracow (in Polish).

Dima D. S., Covaciu, D. and Chiru, A. (2014) Validation of simulation and optimization reconstruction in PC Crash with video recorded sample, in: Proc. $3^{\text {rd }}$ International Congress Science and Management of Automotive and Transportation Engineering 2014 Craiova, Romania, SMAT Paper no 2014-MTSRT51, pp. 207-212.

Knopik, L. and Migawa, K. (2017) Optimal age-replacement policy for non-repairable technical objects with warranty, Eksploatacja i Niezawodność - Maintenance and Reliability, vol. 19, no. 2, pp. 172 -178.

Kostek, R. and Aleksandrowicz, P. (2017a) Effect of contact parameters on the pattern of vehicle collisions with a round pillar, in: Engineering Mechanics 2017, Brno University of Technology, Brno, pp. 490-493.

Kostek, R. and Aleksandrowicz, P. (2017b) Identification of the parameters of vehicle contact with a rigid barrier from a crash test, in: Engineering Mechanics 2017, Brno University of Technology, Brno, pp. 494-497.

Kostek, R. and Aleksandrowicz, P. (2017c) Simulation of car collision with an impact block, in: Proc. $11^{\text {th }}$ International Congress of Automotive and Transport Engineering 2017, Pitesti, Romania, IOP 012008, pp. 1-6, doi:10.1088/1757-899X/252/1/012008.

Kostek, R. and Aleksandrowicz, P. (2017d) Simulation of the right-angle car collision based on identified parameters, in: Proc. $11^{\text {th }}$ International Congress of Automotive and Transport Engineering 2017 Pitesti, Romania, IOP 012013, pp. 1-6, doi:10.1088/1757-899X/252/1/012013.

Lambert, J. and Rechnitzer, G. (2002) Review of Truck Safety, Stage 1: Frontal, Side and Rear Underrun Protection, MONASH University, Accident Reasearch Centre, Raport No. 194, Victoria.

Porteš, P., Kučera, P., Pištěk, V., Fojtášek, J. and Zháňal, L. (2017) Modern tools for vehicle development in: Engineering Mechanics 2017, Brno University of Technology, Brno, pp. 54-57.

Semela, M. and Bradáč, A. (2007) Procedure of collision solving in the system of Virtual Crash and options for results validation, in: Proc. $12^{\text {th }}$ International conference of experts - analytics of road accidents 2007, Brno, Czech Republic, pp. 1-19 (in Czech).

Wicher J. (2012) Vehicle and road traffic safety, Publishing House of Communications, Warsaw (in Polish).

Yang, Na., Zhao G. and Zhu Y. (2012) Analysis of Vehicle Crash Compatibility, in: Proc. $3^{\text {rd }}$ International Conference on Digital Manufacturing \& Automation 2012, Guilin, China, vol. 2, pp. 230-232. 